\title{
Reliability of evaluations for the choice of system solutions at the example of automated order- picking systems for bagged goods
}

\author{
DR.-ING. THORSTEN SCHMIDT \\ M.S.I.E. (USA) LARS LEIKING \\ FRAUNHOFER-INSTITUT FÜR MATERIALFLUSS UND LOGISTIK IML, DORTMUND
}

\begin{abstract}
There is a steadily increasing pressure on cost-savings and productivity growth in sectors of order-picking such that the wish for rationalization by automation is rising. Special problems are faced trying to automatize handling operations of order-picking articles packed in bags. The mechanical properties of the objects and their hard-to-predict shape and position represent obstacles and are complicating handling operations. A systematic approach in system design is required. This article deals with the properties of such products under aspects of difficulties arising in automated handling and points out a useful system development methodology.
\end{abstract}

\section{Introduction}

Bag packages are used in the food and cosmetics industry as well as in multiple branches of equipment and machine manufacturing and for electronic parts. In many cases, it is common to pack piece goods which are of small size and of the same kind into bags of plastic film (on which lies the focus of this article) in order to store or transport them. Examples are fasteners like fittings of water-bearing systems or connecting parts for pneumatic and hydraulic devices. When at the same time these articles are often ordered in highly varying numbers, they cannot be packed into cases or cartons in a fixed amount but have to be handled in bags.

Also, the bag package has certain advantages so that it is only reluctantly replaced by other packages, like cartons. These advantages are, for example, low manufacturing and recycling costs, low weight, good volume utilization, manufacturing flexibility in package design and size, waterproof and air-proof package, resistance against chemicals, etc.

Often there is a high pressure on costs in areas of order-picking, at the same time there exists a high potential for rationalization. Automation is an attractive means to make order-picking processes more efficient. There are obstacles though when trying to automatize handling processes of articles packed in bags: Due to the hard-to-detect shape and position of the handling objects, there arise difficulties in image processing which hinder a directed, automated picking as well as other handling actions. A position and shape detection within required tolerance is almost impossible, since in addition, high throughputs have to be realized.

Besides that, the hard-to-predict reaction of the objects on applied forces constrains the deployment of grippers. Furthermore, the packed goods are often stored loosely in boxes or other containers from which they are picked, so that the system developer is faced with the sufficiently known but seldom with justified effort solved difficulty of "grasping out of a box". That is why currently, bagged goods are exclusively picked manually, thus labor-intensively.

Bags are flexible objects, i. e. they can easily be deformed by torsion or bending moments or pressure while they absorb tensile forces relatively well (see [Böger97]). From literature it is known, that flexible parts cause trouble for the automation of handling operations [Hesse96]. For filled bags there is an additional influence of the packaged goods. Some unusual approaches had been made. Turner et al. [Turner94] for example have tried to automatically convey and orientate bags on a bed of air created by a certain alignment of air-jets in order to be able to place them in open slots of a pre-slit card. This intricate device has not been developed much beyond a test rig status though. Whereas nowadays, some manufacturers of packaging machines offer handling equipment in addition to their products which convey bags in a certain number into cartons or to a cartoning process immediately after they are filled.

Since the bags are isolated immediately after filling, handling operations are relatively easy. The actual difficulty arises when a single bag shall be divided off from a heap of loosely stored bags, similar to how they are stored in order-picking zones. In literature hardly any attempts are documented that aim at the automated order-picking of bagged goods. 
The following descriptions shall point out the influences and constraints of automated handling operations for the order-picking of bags imposed by the product and package properties. As not all of the possible bag designs can be considered special examples are picked up. When developing automated systems it is necessary to proceed systematically. So subsequently hints for a system development methodology are given in order to approach the difficult task of developing a system for the automated handling of bags.

\section{Influence Parameters}

In the following, an overview of the manufacturing process of the package shall be given and physical properties as well as operating figures in demand and storage shall be discussed.

\section{Manufacturing of Bag Packages}

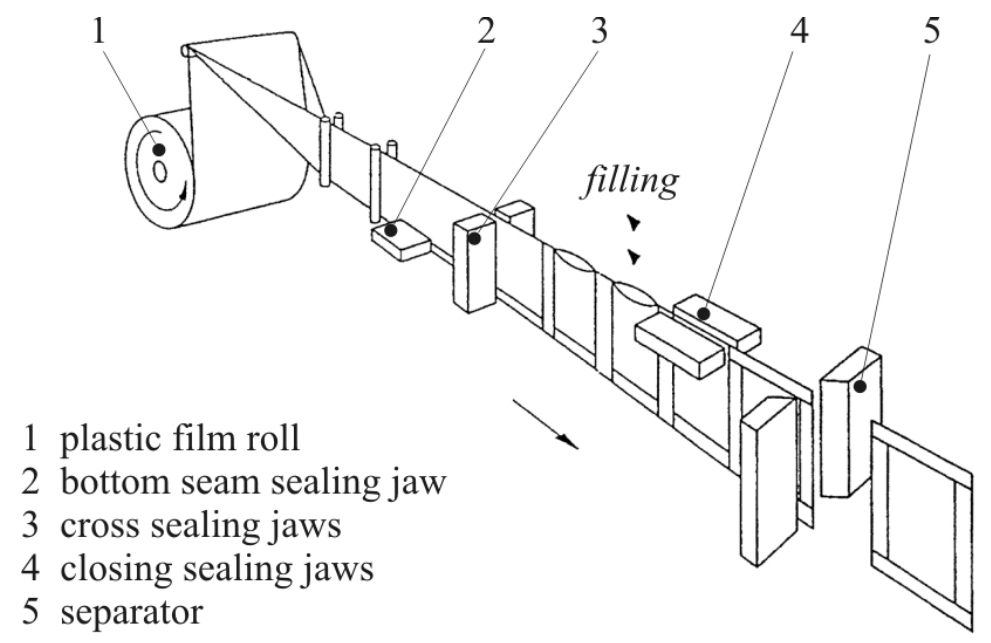

Fig. 1: Horizontal Form Fill Seal Machine [DIN00]

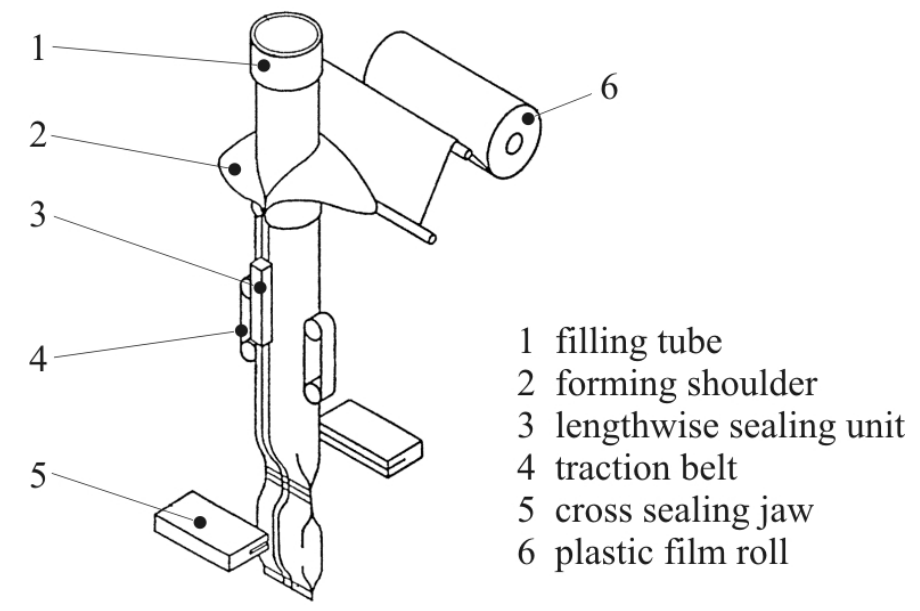

Fig. 2: Vertical Form Fill Seal Machine [DIN00]

To get an impression of the chances for a design which is suitable for automated handling, at first the manufacturing processes should be analyzed. As it is impossible to list and describe all the types of packaging machines and their variants here, two of the most common principles of bag package manufacturing shall be discussed instead.

Figure 1 shows the principle of Horizontal Form Fill Seal Machines. For the horizontal filling the plastic film is pulled off a roll at first. Depending on the requirements the bottom can be 
sealed1 or welded2 subsequently. After that the sheet is sealed across the feed direction. Between the cross seals the sheet is opened for filling. Eventually, the filled chamber is closed and a bag is cut off the line. For the vertical filling process (fig. 2) the film is pulled over a forming shoulder in the beginning, so that it is formed to a hose around the filling tube, and sealed longitudinally. After the filling the cross seal jaws close the bag. Often a knife is carried along with the jaws and cuts off the bag at the same time.
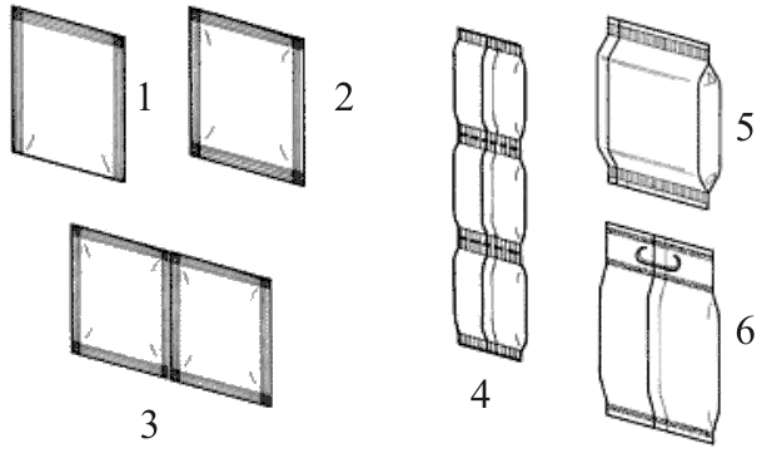
13 -side sealed bag
2 4-side sealed bag
3 double sealed bag
4 chain of bags
5 gusseted bag
6 carry handle bag

Fig. 3: Some producable flat bags [rov05]

In most of the cases the package material consists of polyethylen (PE), polypropylen (PP), or polyethylenterphthalat (PET) Ahlhaus97]. The film can have one or more different layers (composite film) which take on different functions. (printability, heat sealing, etc.). Figure shows a few of the possible flat3 bag designs that can be manufactured with the described measures. With a little extra effort bottom parts can be added on which the bag can stand. The bag design is advantageous for handling operations, because it helps keeping bags in a desired orientation. It should be obvious, though, that costs and cycle times increase for this design and the higher stiffness of the package leads to the consumption of more space in storage for the same number of articles. Analogously, there are similar trade-offs to any other measure in bag design.

Apart from bottom parts, there exist several other design possibilities. Every measure which has the objective to support the major rule of automation (to keep up a once achieved state of order of the handling object) is of help. Changes that can be made with relatively little effort are:

- bag length and width

- width of the seals

- impregnation of the seals (or other parts of the plastic film)

- filling level

- chaining up of bags

An increase of the filling is equivalent to increase in stiffness of the bag. It is easy to see that a tightly filled bag tends to tangle less with other bags than a slightly filled one. Chaining up of bags is demonstrated by example 4 in figure 3. Usually the number of bags which can be connected in this way is unlimited.

1 Heat Sealing is a process in which thermoplastic melting layers of package material are connected by hot pressing and is applicable where a welding process is infeasible due to the pairing of package material [NN89].

2 In the following, the term sealing shall be used representatively for both processes.

3 Flat bags are bags without a constructive bottom part [BGS03]. 


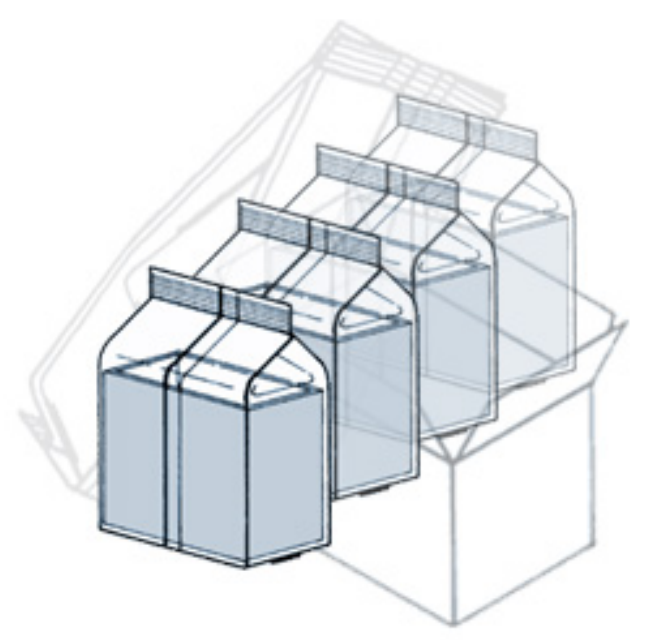

Fig. 4: Standing block bottom bags [rov05]

Apart from the shape of the bag some optical and material properties can be influenced:

- translucency

- imprint

- application of shrink film

- thickness of the film (effect on stiffness and strength)

To improve automatic object recognition (color sensors, light barriers, etc.) it can be advantageous to color or imprint the film in a special way or to adjust a certain translucency. These attributes can be achieved without any changes in the packaging process, only the package material roll has to be exchanged. The other properties can have an effect on the manufacturing process, machine and process parameters may have to be adjusted (e. g. change of sealing time to thicker film) or additional devices be implemented (heat blowers for shrink film). To a limited extend also friction coefficients can be adjusted.

It has to be ensured that advantages and disadvantages due to changes are evaluated in advance. An increase of the filling level for example may contribute to the improvement of handling operations on the one hand, but on the other hand this may lead to a greater consumption of space for storing bags loosely in a container since the number of possible arrangements of the parts is restricted.

\section{Warehouse Operations}

To get a better understanding of the order-picking process, function structures of the superordinate material flow process and the order-picking process shall be set up using the standardized symbolism of the VDI-guideline [VDI90]. Figure 5 shows a possible abstraction of the material flow processes from feeding the parts to the packaging process to order-picking which is represented by the function "allocate".

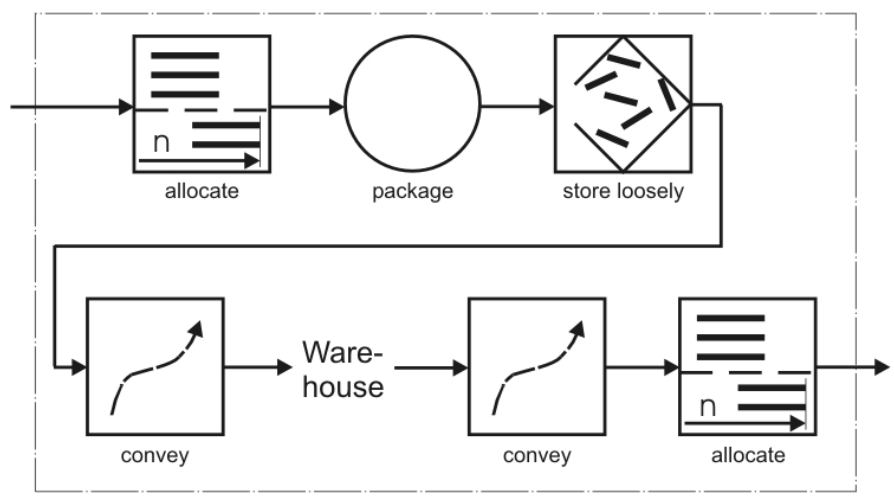

Fig. 5. Subordinate material flow 


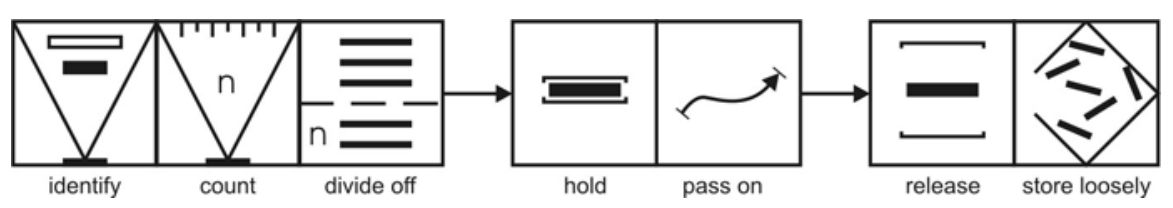

Fig. 6: The order-picking process

Depending on the strategy, the functions "convey" or the storage in a warehouse can be omitted. The order-picking process from identifying the correct article to accumulating orders into order-picking containers can be further particularized as shown in figure 5. Here, too, an omission of some functions is possible. According to the rules of methodical system development out of these function structures a morphological box can be created in order to develop solution variants. The morphological box is sufficiently documented in literature (e. g. [Pahl04]) so that it is not discussed in detail at this place.

It is required that the conveying and handling devices to be designed meet the requirements which had been set up for a specific case, and an efficient material flow. The development of a part of a system has an effect on the entire material flow und has to be optimized with respect to the efficiency of the entire system. Thus additionally, adequate loading devices play a role and have to be considered in the system design, and the properties of the products and their package define the options and constraints for the system design to a great extend. Furthermore, not only the shape and the physical properties are to be considered, but for the design of handling equipment the required cycle times, and statistical/probabilistic data of the number of bags per order of a certain article are of special interest. Such data determine, for example, what type of drive and control technologies are applicable and how the processes of dividing off a certain number of bags has to be carried out (whether e. g. several bags have to be divided off at the same time).

\section{Methodical Approach in Design}

\section{Difficulties in Evaluating the Cost-Efficiency of Measures}

Before the implementation an evaluation of the effectiveness of measures of rationalizing orderpicking zones is indispensable but not that easy to conduct. With costing methods like investment calculations only monetary aspects can be evaluated. Beyond that, there are effects which are difficult to quantify [Becker93], like the use of ergonomic machine design or the improvement of a company's image by introducing new technologies (which is often the reason for implementing robot systems). Furthermore, a great deal of the quantifiable evaluation criteria is not readily available before a realization.

To make a useful decision the sum of strategic, technical, economic, and social aspects, between which there may exist complex interdependencies, have to be considered. In order to take all of these influences into account, methods similar to the value benefit analysis seem to be attractive means. These methods are useful tools for decision making in combination with cost accounting. They offer the opportunity to also include qualitative properties and effects or such which can not yet be calculated due to an early state of development into the comparative evaluation of measures.

The application of value-benefit-analysis-like methods is widely spread today. The field of applications spans from investment decision making for production systems [Köhrmann97] to federal income tax law [Schmidt02], evaluation of software systems [Algedri98] and to project evaluation [Schulte02].

\section{Evaluation of Variants}

A suitable modification of the value benefit analysis by [Zangemeister76] for the evaluation of solution variants, whether in a concept or an already detailed draft form, can be described as follows: First, a list of $K$ relevant goal criteria which should preferably be independent of each other is to be set up. These are then divided into $T$ technical and $K-T$ economic criteria and 
weighted relative to each other so that for the weights $g_{m}^{t}$ and $g_{m}^{w}$ of the technical and economic criteria the following applies:

$$
\begin{aligned}
& \sum_{m=1}^{T} g_{m}^{t}=\sum_{m=T+1}^{K} g_{m}^{w}=1, \\
& g_{m}^{t}, g_{m}^{w} \geq 0
\end{aligned}
$$

With the additional weight factors and $c^{t} \geq 0$ and $c^{w} \geq 0$ for the technical and economic criteria, for which $c^{t}+c^{w}=1$ applies, it can be stated that:

$$
\begin{aligned}
& g_{m}=\left\{\begin{array}{l}
c^{t} \cdot g_{m}^{t}, m \leq T \\
c^{w} \cdot g_{m}^{w}, m>T
\end{array}\right. \\
& \sum_{m=1}^{K} g_{m}=1 .
\end{aligned}
$$

Every variant $n$ is evaluated with respect to a criterion $m$ with a number (target value) $0 \leq w_{m n} \leq 10$. Depending on the criterion, different methods or value functions can be applied in order to make the evaluation process impartial to at least some extend.

$$
\begin{aligned}
& W_{n}^{t}=\sum_{m=1}^{T} g_{m}^{t} \cdot w_{m n} \\
& W_{n}^{w}=\sum_{m=T+1}^{K} g_{m}^{w} \cdot w_{m n} \\
& W_{n}=\sum_{m=1}^{K} g_{m} \cdot w_{m n} .
\end{aligned}
$$

With these figures the technical $W^{t}$, the economic $W^{w}$, and the total weighted value $W$ per variant $n$ can be determined:

It is assumed that the technical and the economic value are of the same weight so that $W_{n}=\left(W_{n}^{t}+W_{n}^{w}\right) / 2$ is true.

From a list of decision criteria out of the VDI-guideline 3590 [VDI94] the following technical target categories of target criteria have been deduced:

- throughput

- reliability

- ergonomics

- flexibility

- universality

Splitting up these categories yields the target criteria. From "reliability" for example the criteria "reliable control”, "reliable mechanical parts", and "reliable process” can be derived. Categories for economic criteria are as follows:

- acquisition

- operation

The category "recycling" can be added depending on the degree of detailing of the variants so that the entire life cycle of a technical system would be covered. Table 1 shows an example of such an evaluation for five variants of an order-picking system (these shall not be discussed here any further). 
Table 1: Evaluation table

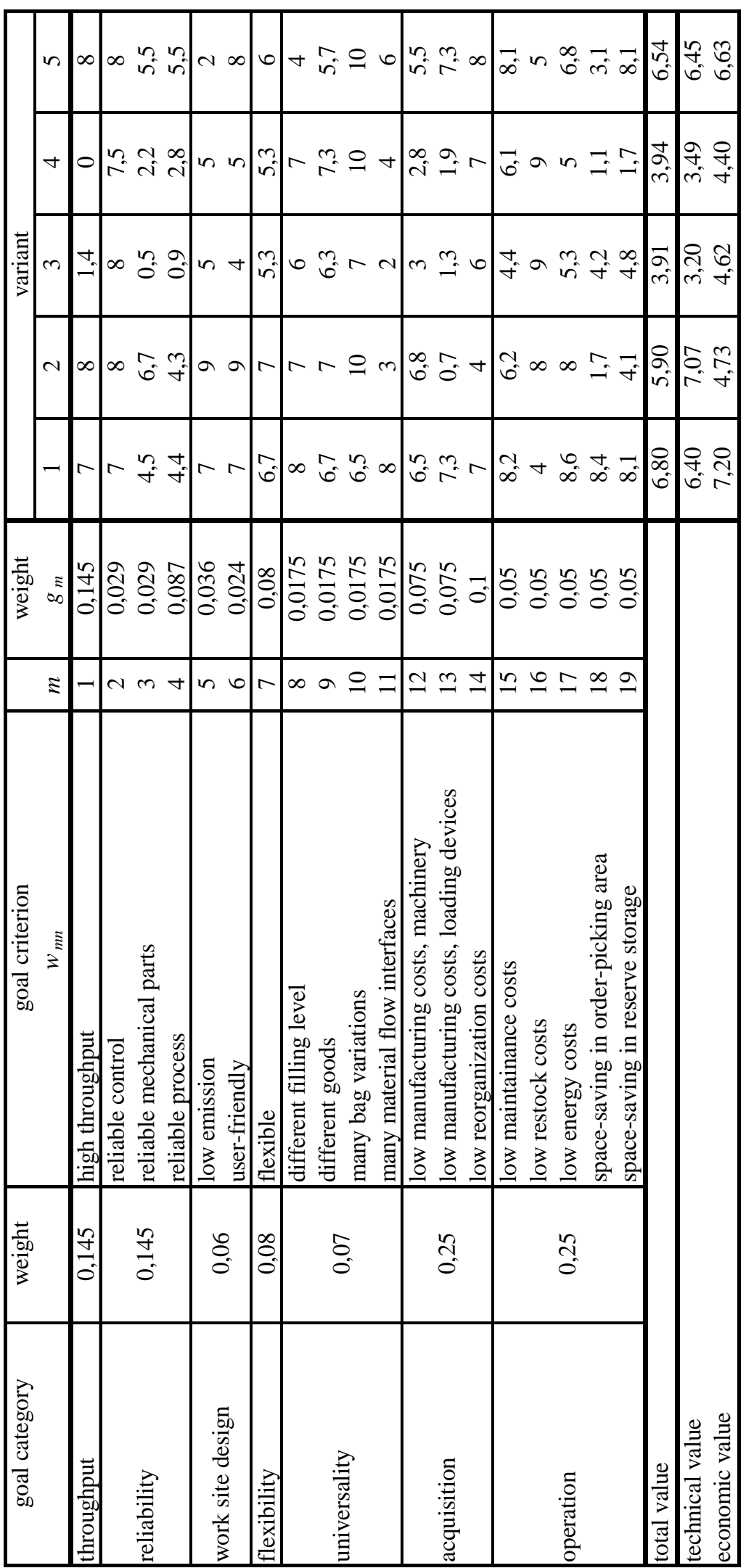




\section{Sensitivity Analysis}

The method described above unfortunately is afflicted with uncertainties depending on the degree of detailing since values of $g_{m}$ as well as $w_{m n}$ have to be estimated. The further the development of the variants proceeds the more exact the properties can be predicted with regard to the target criteria. Usually there remains some uncertainty which puts the stability of the evaluation result in question. To check this stability, sensitivity analyses should be conducted.

\section{Theory of the Sensitivity Analysis Method}

At this place, a procedures which has not yet been documented in literature before is derived and suggested: The determination of suitable variants according to the above-mentioned method can be described mathematically as an optimization progam. In case the most suitable variant $n^{*}$ is defined as the one with the highest total value $W_{n^{*}}=\max _{n} W_{n}$ the following can be written:

$$
\begin{aligned}
& \max \sum_{n} W_{n} x_{n} \\
& \operatorname{mit} \sum_{n} x_{n}=1 \\
& \quad x_{n} \in\{0,1\} \forall n,
\end{aligned}
$$

where all $x_{n}$ are binary decision variables and all other values are coefficients determined by the earlier evaluation process. The set-up of a program for the technical or the economic value is done analogously. The coefficients of the program have been subjectively defined by the values $g_{m}$ and $w_{m n}$, hence, are not certain. To be able to give information on the stability of the solution, it has to be found out which of the values have to be altered by how much in order to change the solution of the evaluation, and it has to be checked how realistic these changes are.

The change of a weight $g_{m}$ is expressed by $d_{m}$. Since $\sum_{m=1}^{K} g_{m}=1$ (see above) it further has to be true that the new weights $g_{m}{ }^{\prime}$ can be written as:

$$
g_{m}^{\prime}=\frac{g_{m}+d_{m}}{1+\sum_{m} d_{m}}
$$

The result of the new total value of a variant $n$ using $w_{m n}=$ const thus is:

$$
W_{n}{ }^{\prime}=\sum_{m} g_{m}{ }^{\prime} w_{m n}=\frac{1}{1+\sum_{m} d_{m}} \sum_{m}\left(g_{m}+d_{m}\right) \cdot w_{m n} \text {. }
$$

It shall be assumed that $d_{m}=d \neq 0$ only applies to one certain $m$ and all other $d_{m}=0$, so that $\sum_{m} d_{m}=d$. The change of the old value $\delta_{m n}=W_{n}{ }^{\prime}-W_{n}$ making use of the definition of $W_{n}$ (see above) can then be formulated as

$$
\delta_{m n}=\frac{d}{1+d} \cdot\left(w_{m n}-W_{n}\right)
$$


A change of the optimal solution now occurs in the case of

$$
\delta_{m n}^{*}+W_{n} \geq \delta_{m n^{*}}^{*}+W_{n^{*}}
$$

for some $n \neq n^{*}$. Plugging in $\delta_{m n}$ yields

$$
d_{m n}^{*} \leq \frac{W_{n}-W_{n^{*}}}{w_{m n^{*}}-W_{m n}}
$$

Plugging this into the equation from above for $g_{m}{ }^{\prime}$ gives $g_{m n}{ }^{*}$, and so the change of the weights $\Delta g_{m n}^{*}=g_{m n}^{*}-g_{m}$ yields

$$
\Delta g_{m n}^{*} \geq \frac{d_{m n}^{*}}{1+d_{m n}^{*}}\left(1-g_{m}\right)
$$

This change of a certain weight of a criterion $m$ also constrains changes in the other weights for which $d_{m}=0$ was set (s. equation (5)). All of the changes generated in this way have to be valid, i. e. the constraints from equations (1) and (2) have to be fulfilled so that it has to be true that

$$
0 \leq g_{m}+\Delta g_{m n}^{*} \leq 1
$$

With this a first tool for the analysis of the coefficients $g_{m}$ of the optimization problem could be derived. Using simple spreadsheet calculations (e. g. using MS-Excel ${ }^{\circledR}$ ) at first for all $n \neq n^{*}$ and all $m$ the values for $d_{m n}^{*}$ and subsequently all $\Delta g_{m n}^{*}$ can be determined. If this analysis yields low values for $\Delta g_{m n}^{*}$, the solution of the optimization program may be considered unstable.

Furthermore, the values $w_{m n}$ have an effect on the coefficients $W_{n}$ of the optimization program. It shall be assumed that again only one value $W_{n}$ with $n \neq n^{*}$ is varied, while all other $w_{m n}$ remain constant. The change of $W_{n}$ is denoted by $\Delta w_{m n}$. To change the optimal solution $n^{*}$, the following must be true:

$$
\Delta w_{m n}^{*}=\frac{W_{n^{*}}-W_{n}}{g_{m n}} .
$$

Among these values, the ones which fulfill the constraint

$$
w_{m n}+\Delta w_{m n}^{*} \leq 10
$$

are considered valid. Conversely, it is possible to lower $w_{m n *}$ by $\Delta w_{m n}^{*}$ in order to change the solution of the above-mentioned optimization program, where

$$
0 \leq w_{m n}^{*}-\Delta w_{m n}^{*}
$$

must apply. So another tool is to calculate the values $\Delta w_{m n}^{*}$ for all $n \neq n^{*}$ and $m$ on a simple spreadsheet and to detect whether some valid values are so low that the original solution is to be considered unstable. 
In addition, the values $\Delta w_{m n}^{*}$ which have the highest corresponding $g_{m}$ will be the lowest since

$$
\delta_{m n}=\sum_{m} g_{m} \Delta w_{m n}^{*}
$$

applies for the change of the evaluation value.

Out of this a further method can be deduced: The values $g_{m}$ are ranked by their size for all $m$. According to this ranking (starting with the highest value) the values $\Delta w_{m n}^{*}$ per variant $n \neq n^{*}$ are changed until the solution $n^{*}$ changes. The number of values which have to be altered until a change of the solution occurs can be used as an indicator for the stability of the solution.

\section{Application of the Method}

The method introduced in the previous section is applied to the values in Table 1 for demonstration. The results of an analysis of the optimum $n^{*}=1$ for the total value with regard to the changes of $g_{m}$ are shown in Table, an analysis of the optimum $n_{t}^{*}=2$ for the technical value in Table 2. An analysis of the economic optimum is redundant in this case, since $n^{*}=n_{w}^{*}$ and $W_{n^{*}}-W_{n}<W_{n^{*}}^{w}-W_{n}^{w} \forall n \neq n^{*}$, such that $\Delta_{g m n^{*}} \leq \Delta g_{m n^{*}}^{w}$. In the tables some cells do not have an entry since $w_{m n^{*}}-w_{m n}=0$ und thus changes in the optimal solution are impossible. Additionally, also values which have been defined as invalid are listed.

Table 2: Required changes $\Delta g_{m n}^{*}$ of the weights of the criteria $g_{m}$ for the change of the solution with respect to the total value $n^{*}=1$

\begin{tabular}{|c|cccc|}
\hline criterion & \multicolumn{4}{|c|}{$\Delta g_{m n}^{*}$ of variant $n$} \\
& 2 & 3 & 4 & 5 \\
\hline 1 & 0,406 & $-0,912$ & $-0,589$ & 0,176 \\
2 & 0,461 & 0,721 & 0,826 & 0,200 \\
3 & 0,283 & $-2,529$ & 4,983 & 0,200 \\
4 & 1,027 & $-4,328$ & 2,075 & 0,174 \\
5 & 0,300 & 3,130 & 3,215 & $-0,053$ \\
6 & 0,304 & $-25,703$ & 3,255 & 0,201 \\
7 & 0,691 & 1,784 & 1,804 & $-0,542$ \\
8 & $-9,136$ & 3,190 & 1,512 & $-0,068$ \\
9 & 0,737 & 1,140 & 0,812 & $-0,344$ \\
10 & 0,201 & 0,838 & 0,442 & $\mathbf{0 , 0 6 8}$ \\
11 & $-0,217$ & $-0,913$ & $-2,455$ & $-0,147$ \\
12 & 0,694 & $-4,385$ & $-3,133$ & $-0,324$ \\
13 & $-0,147$ & $-0,860$ & $-1,039$ & - \\
14 & $-0,387$ & 1,376 & - & 0,185 \\
15 & $-0,782$ & $-3,018$ & 3,587 & 1,545 \\
16 & 0,175 & 0,348 & 0,345 & 0,196 \\
17 & 2,832 & $-6,701$ & $-3,651$ & $-0,160$ \\
18 & $-0,148$ & $-2,096$ & $-0,611$ & $\mathbf{- 0 , 0 4 9}$ \\
19 & $-0,277$ & $-6,701$ & $-0,766$ & - \\
\hline
\end{tabular}

It is defined that valid numbers whose absolute value are less than 0.1 are considered critical so that sufficient stability of the evaluation result of Table 1 can not be verified. In comparison with Table 2 two critical values in Table can be determined. These values are written in bold letters. This means that variant 5 can replace variant 1 as best solution (total value) with only a slight increase in the weight of criterion 10 "many bag variations" or a slight decrease of the weight of 
criterion 18 "space-saving in order-picking area". Table 3 contains no critical values, variant 2 seems to be a stable technically optimal solution.

Table 3: Weight changes $\Delta g_{m n}^{t^{*}}$ of the criteria $g_{m}^{t}$ necessary to achieve the technically optimal solution

\begin{tabular}{|c|cccc|}
\hline criterion & \multicolumn{4}{|c|}{$\Delta g_{m n}^{t^{*}}$ of variant $n$} \\
& 1 & 3 & 4 & 5 \\
\hline 1 & $-1,436$ & $-1,003$ & $-0,574$ & - \\
2 & $-1,906$ & - & 1,095 & - \\
3 & $-0,412$ & $-1,559$ & $-3,653$ & $-1,001$ \\
4 & 0,719 & 6,869 & 1,422 & 0,281 \\
5 & $-0,467$ & $-26,507$ & $-7,858$ & $-0,090$ \\
6 & $-0,479$ & $-3,241$ & $-8,061$ & $-1,542$ \\
7 & 1,523 & 1,500 & 1,601 & $-1,361$ \\
8 & 0,387 & 1,302 & - & $-0,251$ \\
9 & 1,749 & 1,178 & 0,890 & $-0,875$ \\
10 & $-0,228$ & 4,313 & - & - \\
11 & 0,114 & 1,302 & 0,754 & 0,165 \\
\hline
\end{tabular}

The analyses concerning changes of the values $w_{m n}$ and the determination of the $\Delta w_{m n}^{*}$ is shown in Table. For a similar reason, an analysis of the economic optimum is redundant. Only those criteria are shown for which at least one $\Delta w_{m n}^{*} \leq 10$. The corresponding $g_{m}$ are the highest in a ranking of all $g_{m}$ at the same time. The smaller a value $\Delta w_{m n}^{*}$ the higher the rank of its weight $g_{m}$. Here too, invalid values are shown in the table. It is defined now, that critical numbers have an absolute value of less than 4 . Six of the values in Table are critical, i. e. a small increase of the target values for variant 5 of the criteria 1, 4, 7, or 12 and/or a slight decrease of the same values and the values of criteria 13 and 14 for variant 1 can lead to a change of the evaluation result in favour of variant 5. contains no critical values, variant 2 can be considered a stable solution towards changes of the $w_{m n}$.

Table 4: Required alternations $\Delta w_{m n}^{*}$ of the target values $w_{m n}$ to change the optimal solution (total value) $n^{*}=1$

\begin{tabular}{|c|cccc|}
\hline criterion & \multicolumn{4}{|c|}{$\Delta g_{m n}^{t^{*}}$ of variant $n$} \\
& 1 & 3 & 4 & 5 \\
\hline 1 & $-1,436$ & $-1,003$ & $-0,574$ & - \\
2 & $-1,906$ & - & 1,095 & - \\
3 & $-0,412$ & $-1,559$ & $-3,653$ & $-1,001$ \\
4 & 0,719 & 6,869 & 1,422 & 0,281 \\
5 & $-0,467$ & $-26,507$ & $-7,858$ & $-0,090$ \\
6 & $-0,479$ & $-3,241$ & $-8,061$ & $-1,542$ \\
7 & 1,523 & 1,500 & 1,601 & $-1,361$ \\
8 & 0,387 & 1,302 & - & $-0,251$ \\
9 & 1,749 & 1,178 & 0,890 & $-0,875$ \\
10 & $-0,228$ & 4,313 & - & - \\
11 & 0,114 & 1,302 & 0,754 & 0,165 \\
\hline
\end{tabular}


Table 5: Required alternations $\Delta w_{m n}^{t^{*}}$ of the target values $w_{m n}$ to change the technically optimal solution $n^{t^{*}}=2$

\begin{tabular}{|c|cccc|}
\hline criterion & \multicolumn{4}{|c|}{$\Delta w_{m n}^{t^{*}}$ of variant $n$} \\
& 1 & 3 & 4 & 5 \\
\hline 1 & 4,615 & 26,653 & 24,672 & 4,264 \\
4 & 7,692 & 44,422 & 41,121 & 7,107 \\
7 & 8,365 & 48,309 & 44,719 & 7,729 \\
\hline
\end{tabular}

A ranking of the $g_{m}$ and increasing the corresponding $w_{m n}$ by a defined amount of $\Delta w_{m n}^{*}=1$ yields the results in Table. This table shows the number of $w_{m n}$ which have to be altered as defined in order to change the optimal solution. Empty cells imply that a change is impossible by means of this method. Only a few increases for variant 5 are necessary to replace variants 1 and 2 as optima. A similar statement can be made about variant 1 with respect to variant 2 as the technically optimal solution. Whereas variant 2 requires many increases of the described kind in order to get a higher total value than variant 1 . Variant 2 can not replace variant 1 as the economically optimal solution.

Table 6: Number of alternations of $\Delta w_{m n}=1$ of the target values $w_{m n}$ to change an optimal solution

\begin{tabular}{|c|ccccc|}
\hline criterion & \multicolumn{5}{|c|}{ variant $n$} \\
& 1 & 2 & 3 & 4 & 5 \\
\hline$w$ & 4 & - & - & - & 3 \\
$t$ & - & - & - & - & 4 \\
total & - & 14 & - & - & 3 \\
\hline
\end{tabular}

\section{Conclusion}

In this article the difficulties that arise when the order-picking of bagged goods packed shall be automated are discussed. Apart from design measures a methodology for the development of handling devices was pointed out. The advantages of this new method are the simple generation of decision parameters with respect to the stability of the result of a comparative evaluation of solution variants and the possibility to automate most of the calculation steps (by a spreadsheet computer program for example). An arbitrary manual variation of influence parameters of the evaluation thus becomes superfluous.

A project at the Fraunhofer IML deals with the automated handling and order-picking of goods packed in bags. Currently, market analyses are being prepared, which shall provide additional background knowledge and help to align research activities with the industry's needs, so that an existing all-purpose list of requirements can be verified and complemented. This list serves as a basis for system developments in which the presented methodology is used and enhanced. In this way first drafts of system solutions could be worked out, an implementation of a prototype is planned. It shall be emphasized that the evaluation and sensitivity analyses emerged along with this concrete project, but in general it can be completely assigned to other development and planning tasks. 


\section{Literature}

[Ahlhaus97]

[Algedri98]

[Becker93]

[Bleisch03]

[Böger97]

[DIN00]

[Hesse96]

[Köhrmann97]

[NN99]

[Pahl04]

[Schulte02]

[Schmidt02]

[Turner94]

[VDI90]

[VDI02]

[Zangemeister76]
Ahlhaus, Otto E.: Verpackung mit Kunststoffen. München: Hanser, 1997

Algedri, Jamal; Frieling, Ekkehart: Beurteilung rechnergestützter FMEASysteme. In: QZ - Qualitität und Zuverlässigkeit (1998) 12, pp. 1490-1495

Becker, Thomas: Automatische Kommissionierung - Eignungskriterien und Wirtschaftlichkeitsnachweis. Dortmund: LogBuch 1993

Bleisch, Günter (editor): Lexikon Verpackungstechnik. 1st edition. Heidelberg: Hüthig, 2003

Böger, Thomas. Beitrag zur Projektierung von Greifelementen für die Handhabung flächiger, biegeweicher Materialien. Dissertation. Dortmund: Praxiswissen Verlag 1998

DIN EN 415-3: Sicherheit von Verpackungsmaschinen - Part 3: Form-, Füllund Verschließmaschinen. Berlin: Beuth October 2000

Hesse, Stefan: Praxiswissen Handhabungstechnik in 36 Lektionen. Renningen: Expert Verlag 1996

Köhrmann, C.; Schimmelpfeng, Katja: Anwendung der Nutzwertanalyse im Bereich von Investitionsentscheidungen für Produktionssysteme unter besonderer Berücksichtigung der Verfügbarkeitssicherung. In: Zeitschrift für Planung \& Unternehmenssteuerung (1997) 4, pp. 395-406

N.N.: Brockhaus-Enzyklopädie - Volume Nine GOT-HERP. 19th edition. Mannheim: Brockhaus 1989

Pahl, Gerhard; Beitz, Wolfgang: Konstruktionslehre - Methoden und Anwendung. 6th edition. Berlin [et al..]: Springer 2004

Schulte, Andreas; Bokermann, Ralf: Projektbewertung mit einem Ansatz der Nutzwertanalyse. Kassel: Ecovast-Verlag, 2002

Schmidt-Liebig, Axel: Gewerbebetrieb, Vermögensverwaltung und Nutzwertanalyse im Einkommenssteuerrecht. In: Betriebs-Berater (2002) 50, pp. 2577-2582

Turner, C.; Davies, A.; Parkin, R. M.; Knight, J. A. G.: Soft Product Assembly and Manipulation. In: IEEC Computing and Control Division Colloquium on Intelligent Automation for Processing Non-Rigid Products (1994) October, pp. $4 / 1-4 / 5$

VDI-Richtlinie 2860: Montage- und Handhabungstechnik Handhabungsfunktionen, Handhabungseinrichtungen; Begriffe, Definitionen, Symbole. Berlin: Beuth May 1990

VDI-Richtlinie 3590: Kommissioniersysteme - Praxisbeispiele. Berlin: Beuth August 2002

] Zangemeister, Christof: Nutzwertanalyse in der Systemtechnik. 4th edition. München: Wittemannsche Buchhandlung 1976 